\title{
SÍNDROME MÃO, PÉ E BOCA CAUSADA PELO VÍRUS COXSACKIE: UMA ANÁLISE DA LITERATURA
}

\author{
HAND, FOOT AND MOUTH SYNDROME CAUSED BY THE COXSACKIE \\ VIRUS: AN ANALYSIS OF LITERATURE
}

\author{
Luana Cristina Chaves Calili ${ }^{1}$ \\ Washington De Souza Leal ${ }^{2}$ \\ Tais da Silva Tosate ${ }^{3}$ \\ Lorhayne Cristina Barbosa de Souza ${ }^{4}$ \\ Jeannelly Mara Perreira Araújo ${ }^{5}$ \\ Mikaely Botelho dos Reis ${ }^{6}$ \\ Vilnara Domingos Marcos ${ }^{7}$ \\ Arilton Januário Bacelar Júnior ${ }^{8}$
}

RESUMO: A síndrome mão-pé-boca e considerada uma doença de alto contágio que acomete em crianças menores de cinco anos de idade, isso porque, ao nascer, os bebês não têm anticorpos. Como os bebês não possuem formação de anticorpos, são alvos de doenças infecciosas, e a síndrome mão, pé e boca é causada pelo vírus do grupo Coxsackie que parte da família dos Enterovírus, sendo diferenciados por seus antígenos e patogenia em grupo A que possuem 23 subtipos, sendo estes os que infectam a pele, boca, unhas e olhos, e grupo B que possuem 6 subtipos, causando infecção no coração, pleura, pâncreas ou fígado. Ambos os grupos podem causar infecções cutâneas, febre e meningite asséptica. Sua transmissão acontece de pessoa para pessoa ou através de alimentos e/ou objetos contaminados. Seus sintomas

\footnotetext{
${ }^{1}$ Graduação em Biomedicina na Faculdade Única -Ipatinga-MG

${ }^{2}$ Graduação em Biomedicina na Faculdade Única -Ipatinga-MG

${ }^{3}$ Graduação em Biomedicina na Faculdade Única -Ipatinga-MG

${ }^{4}$ Graduação em Biomedicina na Faculdade Única -Ipatinga-MG

${ }^{5}$ Graduação em Biomedicina na Faculdade Única -Ipatinga-MG

${ }^{6}$ Graduação em Biomedicina na Faculdade Única -Ipatinga-MG

${ }^{7}$ Graduação em Biomedicina na Faculdade Única -Ipatinga-MG

8 Graduação em Farmácia-Bioquímica pela Universidade de Marília e graduação em DIREITO pela Universidade de Marília. Atualmente é professor da Faculdade Única de Ipatinga na Graduação e Pós Graduação,Ex - Coordenador do núcleo de pós graduação da Universidade Presidente Antônio Carlos que consta um portifólio de 3i cursos, EX-Presidente da CIPA da Universidade Presidente Antônio Carlos, coordenador pós- graduação farmacologia e toxicologia da Universidade Presidente Antônio Carlos, coordenador do Curso de Análises Clínicas Universidade Presidente Antônio Carlos e coordenador do curso de Farmácia da Faculdade Únicade Ipatinga. Tem experiência na área Farmacêutica e Análises Clínicas e Jurídica, Doutorando em Ciêcias Jurídicas e Sociais. Mestre em Energia Nuclear e suas Aplicações pelo Instituto de Pesquisa Nuclear IPEN-USP. Especialista em Direito Público, Especialista em Direito Educacional, Especialista em Gestão de Resíduos do Serviço de Saúde, Especialista em Doenças infectoparasitárias, MBA em Gestão Educacional; Especialista em Análises Clínicas. Ex - Membro da Comissão de Ética do Conselho Regional de Farmácia e Membro da Comissãode Ensino do Conselho Regional de Farmácia de Minas Gerais. Atualmente é professor dos cursos de Biomedicina, Farmácia, Psicologia,Enfermagem e odontologia. ministra os conteúdos de Ciências política, Farmacologia, Psicofarmacologia, Imunologia Básica, Imunologia Clínica, Parasitologiae Microbiologia. Participou da capacitação para os Ítens do Banco Nacional de Ítens(BNI-INEP). Membro da CPA FADIPA.
} 
geralmente surgem após três a sete dias da infecção pelo vírus e pode incluir febre superior à $38^{\circ} \mathrm{C}$, dor de garganta, falta de apetite, diarreia, vômito, e muita salivação. Após dois dias do surgimento dos primeiros sintomas, aparecem aftas dolorosas na boca e bolhas nas mãos, pés e em alguns casos nas regiões intimas, causando coceira. Seu diagnóstico e feito pelo pediatra ou clínico geral por meio de análise dos sintomas e manchas. $\mathrm{O}$ tratamento da Síndrome pode ser feito com remédios para febre, como o paracetamol e anti-inflamatórios, mantendo seu uso durante sete dias e incluindo o distanciamento da criança para que não transmita e dissemine a doença para um determinado grupo.

Palavras-Chave: Coxsackie. Síndrome mão. Pé e boca. Enterovírus.

ABSTRACT: The hand-foot-mouth syndrome is considered a highly contagious disease that affects children under five years of age, because, at birth, babies do not have antibodies. As babies do not have antibody formation, they are targets of infectious diseases, and the hand, foot and mouth syndrome are caused by the Coxsackie group virus that is part of the Enterovirus family, being differentiated by their antigens and pathogenesis in group $A$ that have 23 subtypes, which are those that infect the skin, mouth, nails and eyes, and group B, which have 6 subtypes, causing infection in the heart, pleura, pancreas or liver. Both groups can cause skin infections, fever and aseptic meningitis. Its transmission happens from person to person or through contaminated food and/or objects. Its symptoms usually appear within three to seven days of infection with the virus and can include fever above $38^{\circ} \mathrm{C}$, sore throat, poor appetite, diarrhea, vomiting, and excessive salivation. Two days after the onset of the first symptoms, painful canker sores appear in the mouth and blisters on the hands, feet and, in some cases, in the intimate regions, causing itching. Its diagnosis is made by the pediatrician or general practitioner through the analysis of symptoms and spots. The treatment of the Syndrome can be done with medicines for fever, such as paracetamol and anti-inflammatory drugs, maintaining its use for seven days and including the distance from the child so that it does not transmit and spread the disease to a certain group

Keywords: Coxsackie.Hand. Foot and mouth syndrome. Enteroviruses.

\section{INTRODUÇÃO}

A Síndrome Mão, Pé e Boca é uma doença de origem viral, altamente contagiosa, causada pelo vírus Coxsackieda família dos Enterovius que tem o homem como único hospedeiro. Acomete principalmente crianças nos primeiros cinco anos de vida. Sua transmissão ocorre através do contato com pessoa contaminada, por via fecal-oral ou gotículas de saliva. Em alguns casos pode ocorrer a contaminação indireta, por meio de alimentos e objetos contaminados. Apesar de ser uma doença 
comum em crianças, pode acometer adultos, e na maioria dos casos são assintomáticos. ${ }^{\mathrm{I}, 2}$

Sua transmissão ocorre através do contato com pessoa contaminada, por via fecal-oral ou gotículas de saliva. Em alguns casos pode ocorrer a contaminação indireta, por meio de alimentos e objetos contaminados. Os principais sintomas são febre e dor de garganta, que podem ser acompanhados de mal-estar e perda de apetite. Após o período de incubação, que dura de três a seis dias, começam a aparecer aftas na região da boca, manchas e bolhas avermelhadas nas mãos, pés e em alguns casos pode atingir as partes intimas. ${ }^{3,4}$

Os sintomas clínicos podem durar de cinco a dez dias, como forma de tratamento pode ser administrados inflamatórios e antitérmicos, em casos mais graves são indicados antivirais. A síndrome pode regredir espontaneamente após alguns dias, sem a necessidade da administração de medicamentos, as manchas e as bolhas podem levar mais tempo para desaparecer por completo.Mesmo após a cura o vírus ainda pode ser transmitido pelas fezes por até quatro semanas. ${ }^{5}$

Para diminuir o risco de contaminação é fundamental, manter a higiene pessoal das crianças, principalmente em escolas e creches. Em caso de indivíduo infectado e recomendado o distanciamento. O diagnostico é realizado na maioria das vezes a partir dos sinais clínicos, na fase inicial da doença os sintomas são parecidos com uma viroseo que pode acabar dificultando. O diagnostico laboratorial é feito a partir de exames clínico como hemograma, PCR e cultura celular. ${ }^{6,7}$

\section{METODOLOGIA}

A pesquisa foi realizada através de um estudo descritivo por meio de uma revisão sistemática sobre a síndrome mão, pé e boca promovida pelo vírus Coxsackie. Foi realizado um levantamento de dados por meio de artigos publicados na internet, nas bases de dados Biblioteca Virtual de Saúde (BVS), SciELO, ScienceDirect e PubMed, com a busca dos seguintes descritores e/ou palavras chave:: "Coxsackie", 
"Síndrome mão, pé e boca" e "Enterovírus". Por meio da estratégia de busca on-line com os descritores anteriormente citados, foram selecionados artigos entre os anos de 2017 a 2021 nas línguas portuguesa, inglesa e espanhola que tivessem acesso integral de forma online. Após a escolha dos artigos, realizou-se uma seleção para filtrar os artigos que se adequem aos objetivos do trabalho. Sendo assim, foi realizada a leitura e análise crítica dos artigos excluindo aqueles estudos que não obedeceram aos critérios de inclusão supracitados, além dos estudos duplicados encontrados simultaneamente em duas ou mais bases de dados, além de resultados de um mesmo artigo publicado em mais de uma língua. Outrossim, outras fontes foram usadas para compor esse trabalho, como dados retirados do site da Sociedade Brasileira de Pediatria e de revistas online como a Archivesof Health Investigation e a revista de Ciências da Saúde Nova Esperança.

\section{DISCUSSÃO}

\section{I Síndrome mão, pé e boca}

A síndrome mão-pé-boca é uma infecção viral e benigna que embora possa acometer adultos, é mais comum na infância em crianças com até 5 anos de idade causando manifestações clínicas como febre e odinofagia, quando o sistema imunológico ainda não está "forte" o bastante. Em alguns casos, há evolução das complicações para uma infecção no SNC (Sistema Nervoso Central), e mesmo que sejam raros os casos, pode levar o paciente a óbito. Os surtos do vírus ocorrem com maior frequência no verão, outono e em áreas tropicais, onde temos um número significativo de casos da doença o ano inteiro. ${ }^{2,3}$

Alguns estudos demonstraram que os agentes etiológicos da DMPB sofreram alterações ao longo do tempo com circulação de diversos sorotipos em diferentes localidades. As alterações climáticas têm grande influência na ocorrência de surtos da DMPB em alguns países da Ásia. Entretanto, medidas governamentais e ações de vigilância são de extrema importância e necessidade no Brasil, para coletar maiores informações da síndrome em relação surtos e evolução de suas complicações. ${ }^{8}$ 
Pertencentes a família Picornaviridae, o vírus Coxsackie Aı6 ou Enterovírus7i,pode ser encontrado por todo o mundo e é responsável por causar a síndrome mão-pé-boca. A doença pode ter seu surgimento por vários tipos de enterovírus (EV), classificados em cinco espécies: Poliovírus e EV A, B, C e D c e através dos sorotipos A5, A9, Aıo e ecovirus 9, porém, o CoxsackieA ı6 (CAı6) e oenterovírus 7I $\left(E_{7 \mathrm{I}}\right)$ são os principais causadores da patologia. ${ }^{2}$

Figura r. Representação pelo Diagrama de Venn para identificação dos gêneros pertencentes à família Picornaviridae que infectam humanos e animais.

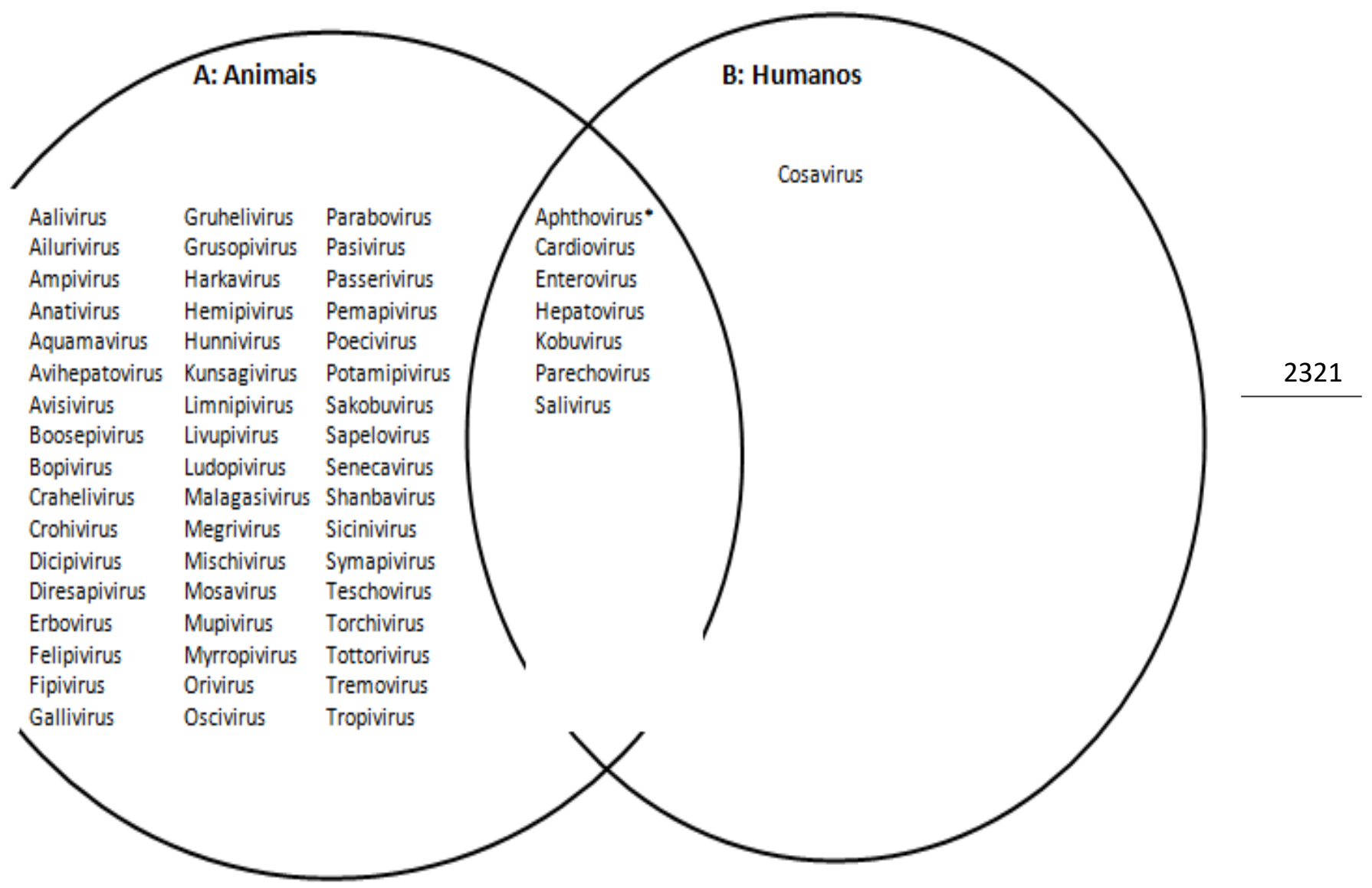

$\mathrm{Na}$ figura I está em representação no círculo A estão os gêneros que são detectados somente animais. No círculo B está representado ogênero encontrado apenas em humanos. Já na congruência estão os gêneros que podem ser achados tanto nos animais quanto nos seres humanos. O gênero Aphthovirus raramente infecta humanos. ${ }^{9}$ 
$\mathrm{Na}$ tabela I podemos ver a classificação dos gêneros infectantes como o Enterovírus7ı, o CoxsackieA6 que também é um dos agentes causadores da doença, assim como outras cepas do vírus, são elas: $\mathrm{A}_{5}, \mathrm{~A}_{7}, \mathrm{~A}_{9}, \mathrm{~A}_{1}, \mathrm{~B}_{2}$ e $\mathrm{B}_{5}$, sendo o Coxsackievirus AI6 o principal agente etiológico e o enterovírus 7I diretamente associado às complicações neurológicas ecardiopulmonares. ${ }^{\mathrm{I}}$

Tabela I- Classificação do gênero enterovirus que infectam humanos

\begin{tabular}{|c|c|c|}
\hline Espécie & & Sorotipos \\
\hline \multirow[t]{4}{*}{ Enterovirus } & A & $\begin{array}{l}\text { coxsackievirusA2 (CV-A2) CV-A3, CV-A4, CV-A5, CVA6, } \\
\text { CV-A7, CV-A8, CV-Aı, CV-Aı2, CV-Aı4, CVAı6; } \\
\text { enterovirus A-7ı (EV-A7ı), EV-A76, EV-A89, EVA9o, EV- } \\
\text { A9ı, EV-Aı14, EV-Aı19, EV-Aı2o, EVAı2ı. }\end{array}$ \\
\hline & B & $\begin{array}{l}\text { coxsackievirus BI (CV-BI), CV-B2, CV-B3, CV-B4, } \\
\text { CV-B5, CV-B6, CV-A9; echovirus I (E-1), E-2, E-3, E4, } \\
\text { E-5, E-6, E-7, E-9, E-11, E-12, E-13, E-14, E-15, Eı6, } \\
\text { E-17, E-18, E-19, E-20,E21,E-24, E-25, E-26, E27, E29, E-30, E-31, } \\
\text { E-32, E-33; enterovirus B69 (EVB69),EV-B73, EV-B74, EV-B75, } \\
\text { EV-B77, EV-B88, EVB93,EV-B97, EVB98, EV-Bıo, EV-Bıг, } \\
\text { EV-Bı66, EVBı7, EV-Bı1 }\end{array}$ \\
\hline & $\mathrm{C}$ & $\begin{array}{l}\text { poliovirus I (PV-I), PV-2, PV-3; coxsackievirus A I } \\
\text { (CV-Ai), CV-Air, CV-Ai3, CV-Ai7, CV-Ai9, CV-A2o, } \\
\text { CV-A21, CV-A22, CV-A24; enterovirus C 95 (EV-C95), } \\
\text { EV-C96, EV-C99, EV-Cio2, EV-Cio4, EV-Cio5, } \\
\text { EVCio9, EV-Cir3, EV-Ci16 EV-117, EV-Cir8. }\end{array}$ \\
\hline & $\mathrm{D}$ & enterovirus EV-D68, EV-D70, EV-D94, EV-DiII \\
\hline
\end{tabular}




\begin{tabular}{|c|c|c|}
\hline \multirow[t]{3}{*}{ Rinovirus } & A & 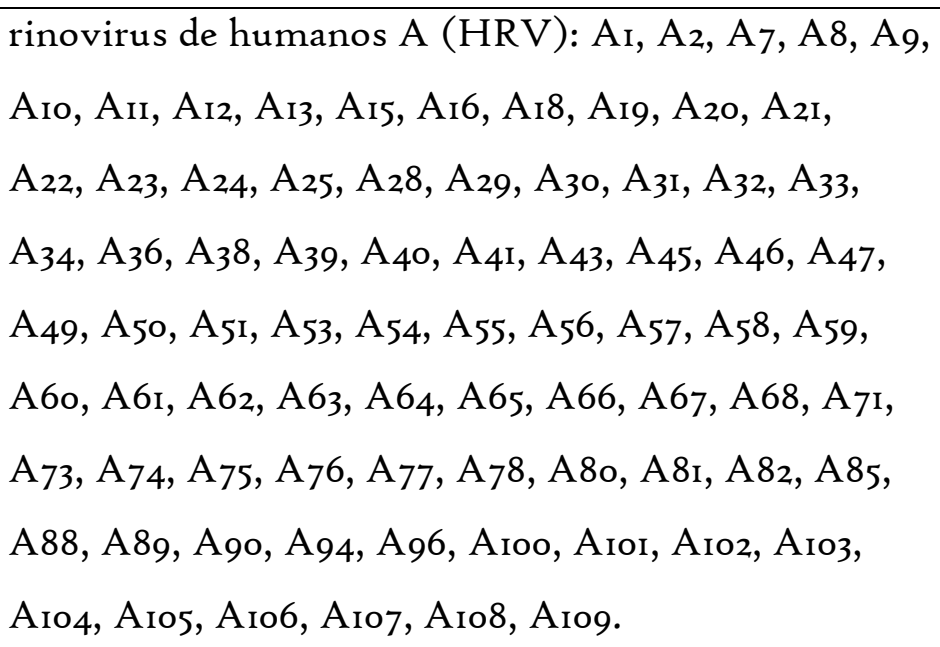 \\
\hline & B & 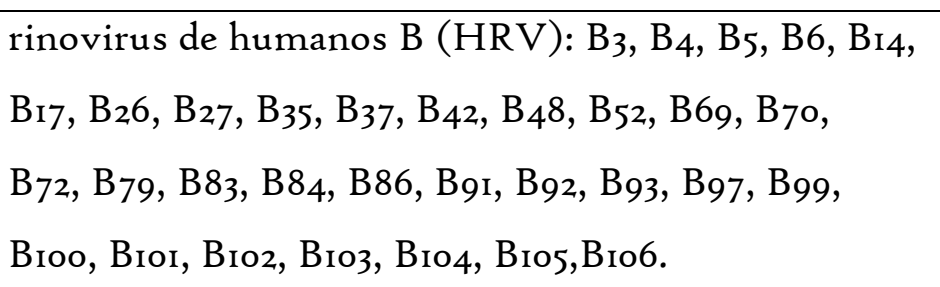 \\
\hline & C & rinovirus de humanos $\mathrm{C}$ : $\mathrm{HRV}-\mathrm{C}_{1}-\mathrm{C}_{57}$ \\
\hline
\end{tabular}

Fonte: Adaptado de: JORGE, 2019.

\subsection{Sinais característicos}

O período de incubação para esta síndrome é de três a seis dias, após esse período podem surgir os primeiros sintomas, como febre e lesões bucais dolorosas. Os especialistas mais procurados para diagnosticar a doença geralmente são os infectologistas, o pediatra e o clínico geral. Os primeiros sintomas geralmente são dor de garganta e febre baixa, que fica por volta de $38^{\circ} \mathrm{C} .^{\text {Io }}$

Também é muito frequente que a criança infectada sinta mal-estar e tenha perda de apetite. A DMPB é caracterizada por lesões cutâneas, úlceras na mucosa oral, causando manchas vermelhas com bolhas (figura 2), que se tornam ulceradas principalmente na língua, gengivas e no interior das bochechas, as quais são cobertas por uma pseudomembrana amarelada, dor durante a deglutição de alimentos ou líquidos, causando febre como outras infecções, dor na região boca, abdominal e sintomas respiratórios 


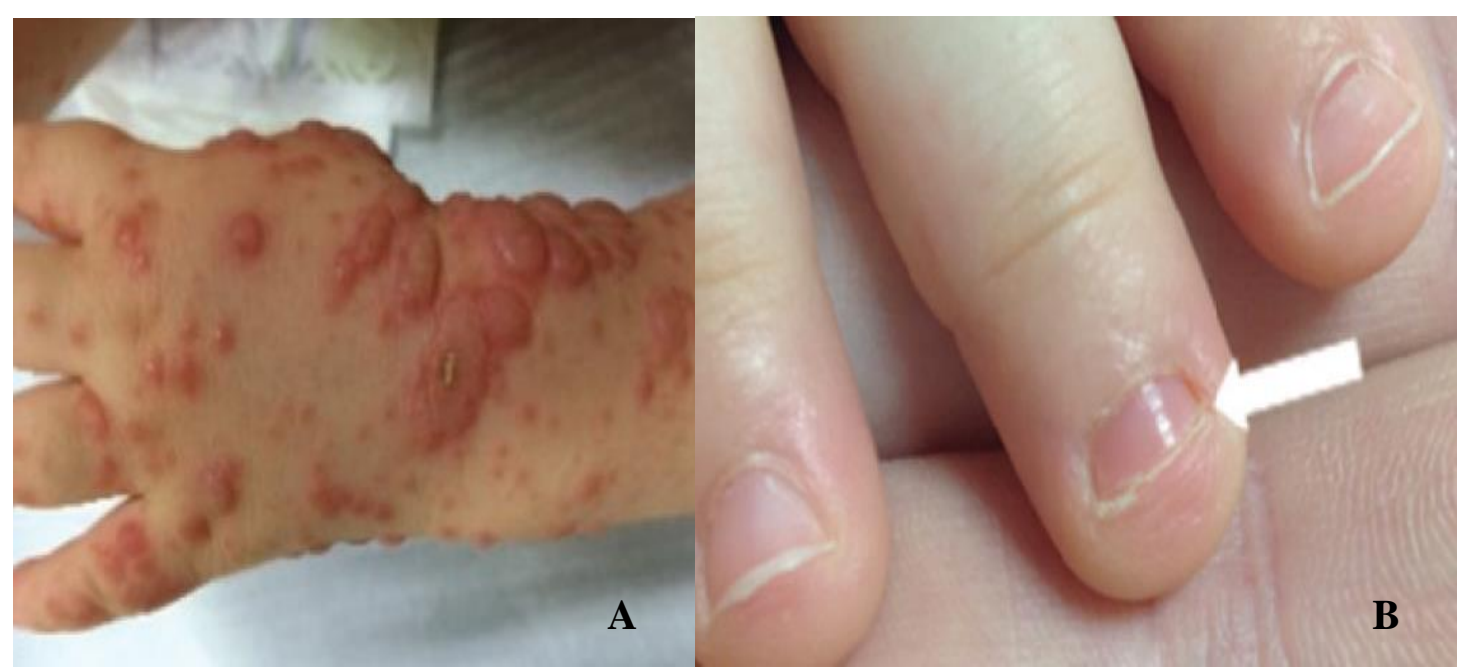

fonte: Departamento Científico de Dermatologia (2019-2021).

A) Exantema vesicobolhoso com envolvimento simétrico;

B) Unha em recuperação, após onicomadeseperioral, face palmar e dorsal das mãos.

Existem várias formas de transmissão do vírus, sendo ele transmitido de mãe para feto, por contato com secreções das vias respiratórias, secreções de feridas dos pés e das mãos, pelo contato com as fezes da pessoa infectada e por objetos ou alimentos que estejam contaminados. ${ }^{2}$

Normalmente a fase de maior contaminação é na primeira semana em que a criança adquiriu a doença e mesmo após a cura, o paciente ainda pode apresentar liberação do vírus pelas fezes, o que o mantém contagioso por vários dias ou até semanas mesmo os sintomas terem desaparecido. A maioria dos adultos que contraem o vírus Coxsackie muitas vezes não desenvolvem os sintomas, mas podem ser transmissores assintomáticos do vírus. ${ }^{\text {II }}$

\subsection{Epidemiologia}

Nos últimos dez anos foram relatados em vários países como o Japão, Malásia, Cingapura, China. No Brasil houve aumento dos casos no Brasil, com 
notificação de surtos o que gerou preocupação pela disseminação da doença. Em 2019 foram mais de 230 casos, nos municípios de Salvador-BA foram encontrados 50 casos; Entre Rios do Oeste -PR (Ioo); Ourinhos - SP (20); São Gabriel -RS (6o) a maioria eram crianças menores de 5 anos. ${ }^{\mathrm{I2}}$

Em todo o mundo os surtos geralmente ocorrem nas estações mis quentes como a primavera, verão e outono, em crianças abaixo dos io anos em ambos gêneros. A Tabela 2 ilustra a evolução dos surtosao longo dos anos ocorridos no continente asiático e Estados Unidos entre 1998 a 2012. ${ }^{1,13}$

Tabela 2: Cronologia da evolução da doença mão-pé-boca no continente Asiático e EUA.

\begin{tabular}{|l|c|c|c|}
\hline \multicolumn{1}{|c|}{ Local } & Ano & Número & Mortes \\
\hline Taiwan & 1998 & 1,5 milhão & 78 \\
\hline Linyi & 2007 & 1149 & 3 \\
\hline Fuyang & 2008 & 353 & 22 \\
\hline $\begin{array}{l}\text { China, Singapura, Vietnã, } \\
\text { Mongólia e Brunei }\end{array}$ & 2008 & 30000 & 50 \\
\hline China & 2009 & ${ }^{*} \mathrm{NE}$ & 35 \\
\hline Sul da China & 2010 & 70.000 & 600 \\
\hline EUA & $2011-2012$ & 63 & ${ }^{*} \mathrm{NE}$ \\
\hline
\end{tabular}

Fonte: REPASS et al 2014, WANG et al 2017 apud NAKAO et al 2019.

A doença de Mão Pé e Boca no Brasil não são de notificação compulsória, tornando os dados de disseminação de genótipos e relato de maior gravidade pouco ou quase escassa. Os surtos devem ser notificados. ${ }^{14}$

Apesar dos surtos acontecerem no mundo todo, os países que pertencem o continente asiático e os banhados pelo Pacífico são os que mais possuem ocorrências severas da doença e em grande escala, com surtos anualmente notificados. A OMS, através do Sistema Regional de Vigilância Baseada em Eventos, acompanha os surtos correntes na Ásia e pelo Pacífico. ${ }^{\text {Is }}$ 


\subsection{Diagnóstico}

De acordo com o departamento Científico de Dermatologia (2019-202I) e Departamento Científico de Infectologia (2019-202I) da Sociedade Brasileira de Pediatria,a doença é muito parecida com qualquer quadro de virose comum, sendo impossível detectá-la em seu diagnóstico clínico quando surgem os primeiros sintomas. Após essa fase, começa a surgir lesões características da síndrome, assim, a doença é facilmentediagnosticada, especialmente após o surgimento das manchas vermelhas e bolhas que aparecem no corpo. No hemograma as alterações são inespecíficas, havendo aumento considerável da contagem de leucócitos (leucocitose) e de neutrófilos no sangue (neutrofilia). ${ }^{8}$

A evolução das complicações da síndrome mão-pé-bocasão causadas por alterações do sistema nervoso central (SNC), quando isso ocorre é necessário a realização da radiografia de tórax que em alguns casos é ineficaz, pois pode falhar por não transparecer o comprometimento dos vasos sanguíneos pulmonares, que culminam com edema (intumescimento de tecidos moles decorrente do aumento de líquido intersticial) pulmonar e alterações cardíacas, que de acordo com as autópsias realizadas, têm relação direta com as lesões nos neurônios do sistema nervoso autônomo, que tem como uma de suas funções controlar a vasculatura e em menor intensidade a necrose e degeneração cardíaca que evolui para a falência cardiopulmonar, procedência que ocorre em poucos casos. ${ }^{16}$

Portanto, deve-se ressaltar que nem toda criança que apresenta comprometimento do SNC irá sofrer com a evolução das complicações graves cardiopulmonares, entretanto, alterações do SNC indicam um sinal de alerta. Quando ocorre sudorese fria, pele moteada (alterações dos vasos sanguíneos na pele, causando uma aparência irregular), taquicardia, taquipneia, hipertensão arterial e hiperglicemia em crianças, o risco se encontra elevado para o agravo das complicações, por isto, devem ser internadas imediatamente e monitorizadas. ${ }^{17}$

Segundo a Organização Mundial de Saúde (OMS) e a Sociedade Brasileira de Pediatria (Departamento Científico de Dermatologiae Departamento Científico de 
Infectologia, a confirmação do diagnóstico da infecção por enterovírus é definida através do isolamento e identificação do vírus em cultura celular, o qual antes era considerado o diagnóstico padrão, por métodos sorológicos que determinam a imunidade prévia, os métodos denominam-se sorotipo-específicoscuja função se dá por limitar sua utilização para diagnóstico da doença em sua fase aguda, ou através da identificação do RNA viral por meio da reação em cadeia da polimerase (PCR). ${ }^{18}$ Preconiza-se como diagnóstico padrão o PCR, por apresentar a vantagem de ser mais rápido, detectar todos os enterovírus, até mesmo os que não crescem com facilidade, ter alta sensibilidade (66\% a 100\%) e especificidade (92\% a 100\%). ${ }^{14}$

\subsection{Tratamento}

A doença dura entre uma semana e dez dias, podendo levar a mais tempo para que as manchas e bolhas desapareçam por completo., ${ }^{3,19}$

Os sinais clínicos da doença regridem espontaneamente após alguns dias, por isso na maioria dos casos o tratamento é sintomático e se baseia na administração de medicamentos como anti-inflamatórios e antitérmicos, faz-se necessário também ahidratação oral e vigilância dos sinais e sintomas para que não ocorra possíveis complicações. $^{2}$

Em casos mais graves são indicados alguns medicamentos antivirais, mas somente com a orientação do profissional da saúde está acompanhando o caso da criança portadora da síndrome. ${ }^{20}$

\section{CONSIDERAÇÕES FINAIS}

A doença Mão Pé e Boca ocorre comumente em crianças menores de 5 anos, possui como maior característica o surgimento de manchas e bolhas na pele, e em poucos casos surgem complicações que evoluem para óbito. Ocorre com maior frequência em países com clima tropical e em épocas mais quentes. E o contágio do vírus pode ser evitado através de medidas básicas de higiene, como desinfecção de locais e superfície, higienização correta das mãos. O tratamento é baseado no 
sintoma apresentado, caso ocorra complicações pode se fazer usos de medicamentos como antivirais, se orientado pelo profissional médico. No Brasil, a doença não é de notificação compulsória e os casos acontecem em maior quantidade na Ásia e em países banhados pelo Pacífico.

\section{REFERÊNCIAS BIBLIOGRÁFICAS}

ARRUDA, Mara Lisa Borges et al. Doença mão-pé-boca no adulto: apresentação típica em idade atípica. Revista Portuguesa de Medicina Geral e Familiar, v. 37, n. 3, p. 249-55, 2021

AZEVEDO.A.C; Doenças exantemáticas em idade pediátrica - Revisão teórica. Associação Pediátrica do Minho. v. I. n. I. p. 5-24. 2020.

BARROS.S.S. SILVA.D.O. SOUSA.M.R.N. CAMPELO.F.S. LEAL.E.S. OLIVEIRA.G.A.L. Meningite asséptica e o coxsackievírus associado a síndrome mãopé-boca: estudo da etiologia dos casos notificados no nordeste. Anais do I Congresso Regional de Virologia, Teresina, PI. v.I. n.I. p. I-2. 2019.

CARVALHO.V.O et al; Síndrome mão-pé-boca; Sociedade Brasileira de Pediatria. Documento Científico. Departamento Científico de Dermatologia e Departamento Científico de Infectologia. v. I. n. I. p. I-8. 202I.

CRISTOVAM.M.A.S et al; Síndrome mão-pé-boca; relato de caso. Revista do Médico Residente. V. I6. N.I. p. 42-45. 2014.

COELHO.F. LIMONGE.L. DUARTE.F; Informe epidemiológico da síndrome mão-pé-boca. Diretoria Técnica de Vigilância e Saúde. Coordenadoria de Vigilância a Doenças e Agravo. Centro de Informações Estratégicas de Vigilância em Saúde. V.I. n.I. p. I-3. 2019 .

FERREIRAG.S.B et al; Vivência de aulas práticas nas ações educativas sobre doença mão-pé-boca em pré-escolares da rede municipal - relato de experiência. Anais do fórum de iniciação científica do UNIFUNEC. V.ı. N.ı. 2019. 
JORGE.A.M.V; Doença de mão, pé e boca por enterovírus: revisão da literatura. São Paulo - SP. Secretaria de Estado da Saúde. Coordenadoria de Controle de Doenças. Instituto Adolfo Lutz. P. I-28. Trabalho de Conclusão de Curso.

LUCENA.I.V.S et al; Desafio da odontopediatria no diagnóstico da doença mão, pé e boca: relato de caso. Revista de Ciências da Saúde Nova Esperança. v.I8. n.3. p. 242248. 2020.

MENDONÇA.G.R; Doença mão pé e boca- o que é e como prevenir. Comunicado E.I.I8- Informe de saúde. Comunicado E.I.I8- Informe de saúde; Marginal Anchieta, Km I7; 09696-ooo; São Bernardo do campo- SP. 2018. Disponível em:<https://revistacrescer.globo.com/Criancas/Saude/noticia/20r6/o9/doencamao-pe-boca-o-que-e-ecomoprevenir.html\#: :text=Os\%2oenterov\%C3\%ADrus\%2C\%20como\%20os\%20caus adores,ou\%2ode\%2opreparar\%20as\%2orefei\%C3\%A7\%C3\%B5es.>. Acesso em o9 de agosto de 2021.

NAKAO.P.H et al; Doença mão-pé-boca no atendimento odontopediátrico. Archivesof Health Investigation. v.8. n.12. p.825-831. 2019.

PEREIRA.S.A; SANTOS.S.N; MARQUES.G.J; Doença mão-pé-boca: apresentação atípica. ACTA Pediatria Portuguesa. v.48. n.I. p. I82-183. 2017.

REPASS.G.L. PALMER.W.C. STANCAMPIANO.F.F; Hand, foot, andmouthdisease: identifyingandmanaginganacute viral syndrome. Cleveland ClinicJournalof Medicine. v.8I. n.9. p. 537-543. 2014.

SILVA. FERREIRA.J.A. HAMIDAH.R. JUNIOR.A.M.P. LAERTE.V. Abordagem diagnóstica das doenças exantemáticas na infância. ARCA, Repositório Institucional da FIOCRUZ. v.I. n.I. p. Io-I9. 2012.

TAMAYO.M.R.R et al; Sindrome mãos, pés e boca: casos atendidos no corpo de guarda. Multimed. v. 24. n. I. P. 140-153. 2020. 
TAPPAREL.C

et

$\mathrm{al}$;

Picornavirusandenterovírusdiversitywithassociatedhumandiseases.

Infection,

GeneticsandEvolution. V. I4. n. I. P. 282-293. 2013.

VAISBICH.M.H. TOZZE.R. BALDACCI.E.R. Miosite e rabdomiólise na doença mão-pé-boca na infância. Scielo. Revista Paulista de Pediatria. v.28. n.I. p.Iog-II4. 2021.

WALDMAN.E.A; Enteroviroses emergentes de importância clínica. ResarchGate. Tratado de infectologia. São Paulo, Atheneu, v. I. n.I. p. 240-243. 1996.

WORLD HEALTH ORGANIZATION. REGIONAL OFFICE FOR THE WESTERN PACIFIC. A guide to clinical management and public health response for hand, foot and mouth disease (HFMD). Manila: WHO Regional Office for the Western Pacific, 20II.

XAVIER.J.P.O; JUNIOR.J.C.C.X; Onicomadese secundária à síndrome mão-péboca: relato de dois casos. ABD Anais Brasileiros de Dermatologia. Sociedade Brasileira de Dermatologia. V.I . N. I. P. 266-268. 2020. 